Erratum

\title{
The Catwalk Power: Germany's new foreign image policy
}

\section{Rainer Hülsse}

Journal of International Relations and Development (2009) 12, 427.

doi:10.1057/jird.2009.32

Correction to: Journal of International Relations and Development (2009) 12 , 293-316. doi:10.1057/jird.2009.12

In the above article the following footnote was inadvertently omitted.

Footnote 1: An earlier version of this article has been presented at the ISA Annual Convention 2007 in Chicago. The author would like to thank participants at the discussion there, as well as Gunther Hellmann, Stefano Guzzini and JIRD reviewers for their helpful comments and suggestions. 